\title{
Can Vitamin C Prevent Complex Regional Pain Syndrome in Patients with Wrist Fractures?
}

\author{
A Randomized, Controlled, Multicenter Dose-Response Study
}

By P.E. Zollinger, MD, W.E. Tuinebreijer, MD, PhD, MSc, MA, R.S. Breederveld, MD, PhD, and R.W. Kreis, MD, PhD

Investigation performed at the Department of Surgery, Red Cross Hospital, Beverwijk, The Netherlands; the Department of Orthopaedics and Surgery, Haga Hospital (Leyenburg), The Hague,

The Netherlands; and the Department of Orthopaedics and Surgery, Reinier de Graaf Group, Delft, The Netherlands

\begin{abstract}
Background: Complex regional pain syndrome type I is treated symptomatically. A protective effect of vitamin C (ascorbic acid) has been reported previously. A dose-response study was designed to evaluate its effect in patients with wrist fractures.
\end{abstract}

Methods: In a double-blind, prospective, multicenter trial, 416 patients with 427 wrist fractures were randomly allocated to treatment with placebo or treatment with 200,500 , or $1500 \mathrm{mg}$ of vitamin C daily for fifty days. The effect of gender, age, fracture type, and cast-related complaints on the occurrence of complex regional pain syndrome was analyzed.

Results: Three hundred and seventeen patients with 328 fractures were randomized to receive vitamin C, and ninetynine patients with ninety-nine fractures were randomized to receive a placebo. The prevalence of complex regional pain syndrome was $2.4 \%$ (eight of 328 ) in the vitamin C group and $10.1 \%$ (ten of ninety-nine) in the placebo group $(p=0.002)$; all of the affected patients were elderly women. Analysis of the different doses of vitamin $C$ showed that the prevalence of complex regional pain syndrome was $4.2 \%$ (four of ninety-six) in the 200-mg group (relative risk, $0.41 ; 95 \%$ confidence interval, 0.13 to 1.27 ), $1.8 \%$ (two of 114) in the 500-mg group (relative risk, $0.17 ; 95 \%$ confidence interval, 0.04 to 0.77 ), and 1.7\% (two of 118) in the 1500-mg group (relative risk, $0.17 ; 95 \%$ confidence interval, 0.04 to 0.75 ). Early cast-related complaints predicted the development of complex regional pain syndrome (relative risk, 5.35; 95\% confidence interval, 2.13 to 13.42).

Conclusions: Vitamin $\mathrm{C}$ reduces the prevalence of complex regional pain syndrome after wrist fractures. A daily dose of $500 \mathrm{mg}$ for fifty days is recommended.

Level of Evidence: Therapeutic Level I. See Instructions to Authors for a complete description of levels of evidence.

$\mathrm{C}$ omplex regional pain syndrome type I (formerly known as reflex sympathetic dystrophy) is treated symptomatically, and the clinical focus is on prevention. In patients who have sustained major trauma, the capacity of homeostasis can be overwhelmed, which can lead to systemic inflammatory response syndrome and multiple-organ distress syndrome $e^{1}$. Systemic inflammatory response syndrome is an excessive inflammatory reaction to an event such as a trauma, burn, or massive infection (as in the case of pancreatitis). These processes appear to be mediated by the same hostderived inflammatory mediators ${ }^{2}$. In an earlier report, we suggested a parallel between burn wounds and the development of complex regional pain syndrome because of the inflammatory reaction and the involved microangiopathy ${ }^{3}$. Complex regional pain syndrome and burn wounds may involve a cascade of deterioration and exaggeration of a similar process.

Disclosure: In support of their research for or preparation of this work, one or more of the authors received, in any one year, outside funding or grants in excess of $\$ 10,000$ from Stichting Achmea Slachtoffer en Samenleving (SASS). Neither they nor a member of their immediate families received payments or other benefits or a commitment or agreement to provide such benefits from a commercial entity. No commercial entity paid or directed, or agreed to pay or direct, any benefits to any research fund, foundation, division, center, clinical practice, or other charitable or nonprofit organization with which the authors, or a member of their immediate families, are affiliated or associated. 
The Journal of Bone \& JOINT SURGERY • JBIS.ORG VOlume 89-A · Number 7 · July 2007

Tanaka et al. reported that, in the clinical setting, ascorbic acid given in high doses during the first twenty-four hours of burn resuscitation significantly reduces resuscitation fluid volume requirements and wound edema ${ }^{4}$. The severity of respiratory dysfunction was also reduced in these patients. The increased vascular permeability in patients with burns is a result of damage to the microvascular endothelial cells caused by oxygen free radicals. Vitamin $\mathrm{C}$ reduces lipid peroxidation, scavenges hydroxyl radicals, protects the capillary endothelium, and inhibits vascular permeability ${ }^{2,3}$. In a previous randomized trial, we reported that treatment with 500 $\mathrm{mg}$ of vitamin $\mathrm{C}$, as compared with placebo, reduced the risk of reflex sympathetic dystrophy in patients with nonoperatively treated wrist fractures ${ }^{3}$. Therefore, we performed a dose-response study to replicate and further evaluate our earlier findings. A steady state in human plasma at doses of $>200 \mathrm{mg}$ of ascorbic acid (vitamin C) per day has been reported $^{5}$. We performed a multicenter dose-response study of patients with all types of wrist fractures that were treated operatively and nonoperatively; the analysis was performed on the basis of the intention-to-treat principle.

\section{Materials and Methods Study Design}

$\Upsilon$ he trial was designed as a multicenter, randomized, controlled study. Three hospitals in The Netherlands participated in the study. The appropriate medical ethics committees of these three hospitals approved the study. An independent physician was appointed (as required under Dutch legislation) for the patients' guidance in case they requested extra information about clinical trials in general or this trial in particular.

Adult patients (defined as those who were eighteen years of age or older) with a wrist fracture who were seen in the emergency department of each hospital were asked by the emergency department physician to participate in the study. Patients with a fracture of both wrists were also included. All wrist fractures were included, independent of treatment choice. Nonoperative treatment consisted of the use of a plaster cast, with the fracture being reduced under local anesthesia if necessary. Operative treatment varied and was applied at the surgeon's discretion.

After informed consent had been obtained, the protocol was initiated in the emergency department. Patients were asked to start the trial medication from that moment, on the day of the fracture. This medication was delivered in a box containing 100 capsules, with two capsules to be taken once daily for fifty days. Patients were allocated randomly to receive either placebo or a dosage of 200,500, or $1500 \mathrm{mg}$ of vitamin C daily.

The pharmacist in one of the participating hospitals, who also made up the medication for the other hospitals, executed the randomization in block form, with blocks of ten according to a table of random numbers. All capsules had the same appearance and taste. The trial was double-blind, with the pharmacist being the only individual with access to the code until the conclusion of the trial.
CAN Vitamin C PREVENT COMPleX Regional Pain Syndrome in Patients With Wrist Fractures?

The end point of the study was defined as the presence of complex regional pain syndrome at any time within one year after the fracture. All participants and physicians were unaware of the treatment allocation. Complex regional pain syndrome was diagnosed by a physician in the treating department and not by anyone involved in the conduct of the trial.

At the time of enrollment, specific study parameters were recorded, including gender, age, the side of the fracture, dominance, fracture type according to the AO/ASIF classification system ${ }^{6}$, dislocation, reduction, the number of the box containing the allocated treatment, drug intake, and the history with respect to previous wrist fractures or earlier episodes of complex regional pain syndrome.

Patients were evaluated after one week, four or five weeks (or when the cast was removed), six or seven weeks, twelve weeks, and twenty-six weeks. After one year, patients were interviewed by telephone or were sent an inquiry letter with a postage-paid envelope for their reply. Fracture treatment was not compromised by the protocol. If necessary, patients were seen more often and/or at other times. Attention was paid to early complaints related to the cast, such as pain, swelling, and numbness.

Complex regional pain syndrome type I was diagnosed if four of the following five symptoms were present at the wrist, including the area distal to the wrist (the hand and fingers), and if they occurred (or increased) after activity: (1) unexplained diffuse pain that was not normal in relation to the stage of fracture treatment, (2) a difference in skin color relative to the other hand and wrist, (3) diffuse edema, (4) a difference in skin temperature relative to the other hand and wrist, and (5) limited active range of motion of the wrist and fingers that was unrelated to the stage of fracture treatment ${ }^{7}$.

If complex regional pain syndrome was diagnosed, the end point of the study was reached and the protocol was terminated to allow for the treatment of complex regional pain syndrome.

\section{Statistical Analysis}

Statistical analysis was performed with SPSS version 11.0 (SPSS, Chicago, Illinois) and MedCalc version 9.2 (MedCalc Software, Mariakerke, Belgium) software on a personal computer. Sample and group sizes were estimated a priori with use of results of our previous study, a planned power of $90 \%$, and a significance level $(\alpha)$ of $0.05^{3}$.

The chi-square test, analysis of variance, and the Student $t$ test were used as applicable for univariate analysis. Measures of association, along with their confidence intervals, were calculated with the Pearson chi-square test or the Fisher exact test. The significant independent variables from the univariate analysis were entered in a multivariate logistic regression with the occurrence of complex regional pain syndrome as a dependent variable. The likelihood ratio backward test was conducted to find the best-fit model by selecting the variables one by one. The probability for entry was set at 0.05 , and the probability for removal was set at 0.10 .

Kaplan-Meier curves with 95\% confidence intervals 
The Journal of Bone \& JOINT SURGERY • JBIS. ORG VOLUMe 89-A · Number 7 • JULY 2007
Can Vitamin C Prevent Complex Regional Pain Syndrome in Patients With Wrist Fractures? were generated to show the time between the fracture and the diagnosis of complex regional pain syndrome. The curves for the placebo and vitamin $\mathrm{C}$ groups were compared with use of a log-rank test.

\section{Results}

B etween January 2001 and December 2004, we enrolled 416 B patients with 427 fractures from a total population of 2137 patients with wrist fractures who presented to the three emergency departments at the three hospitals. The follow-up period ended in December 2005.

Ten patients had a bilateral fracture, and one had an ipsilateral refracture. All fractures were assessed individually. None of the randomized patients were excluded from the study. No adverse events occurred.

Randomization involved 416 patients from the three centers: 317 patients with 328 fractures received vitamin C, and ninety-nine patients with ninety-nine fractures received a placebo. The trial profile is shown in Figure 1. The 1721 patients who were excluded comprised 463 patients who refused to take part for various reasons, 297 patients who wanted to be sure that they received vitamin $\mathrm{C}$, and 961 patients who had not been invited to take part in the study.

The patients who were given vitamin $\mathrm{C}$ and those who were given a placebo did not differ significantly in terms of demographic characteristics (Table I). Analysis of the groups receiving the three different doses of vitamin $\mathrm{C}$ and the placebo showed no significant differences with regard to gender, age, the side of the fracture, dominance, fracture type, dislocation, reduction, or treatment modality (Table I).

After one year, all patients were interviewed by telephone, with the exception of eighteen patients who received an inquiry letter and one patient who was visited at home. It was not necessary to see any of the patients in the outpatient

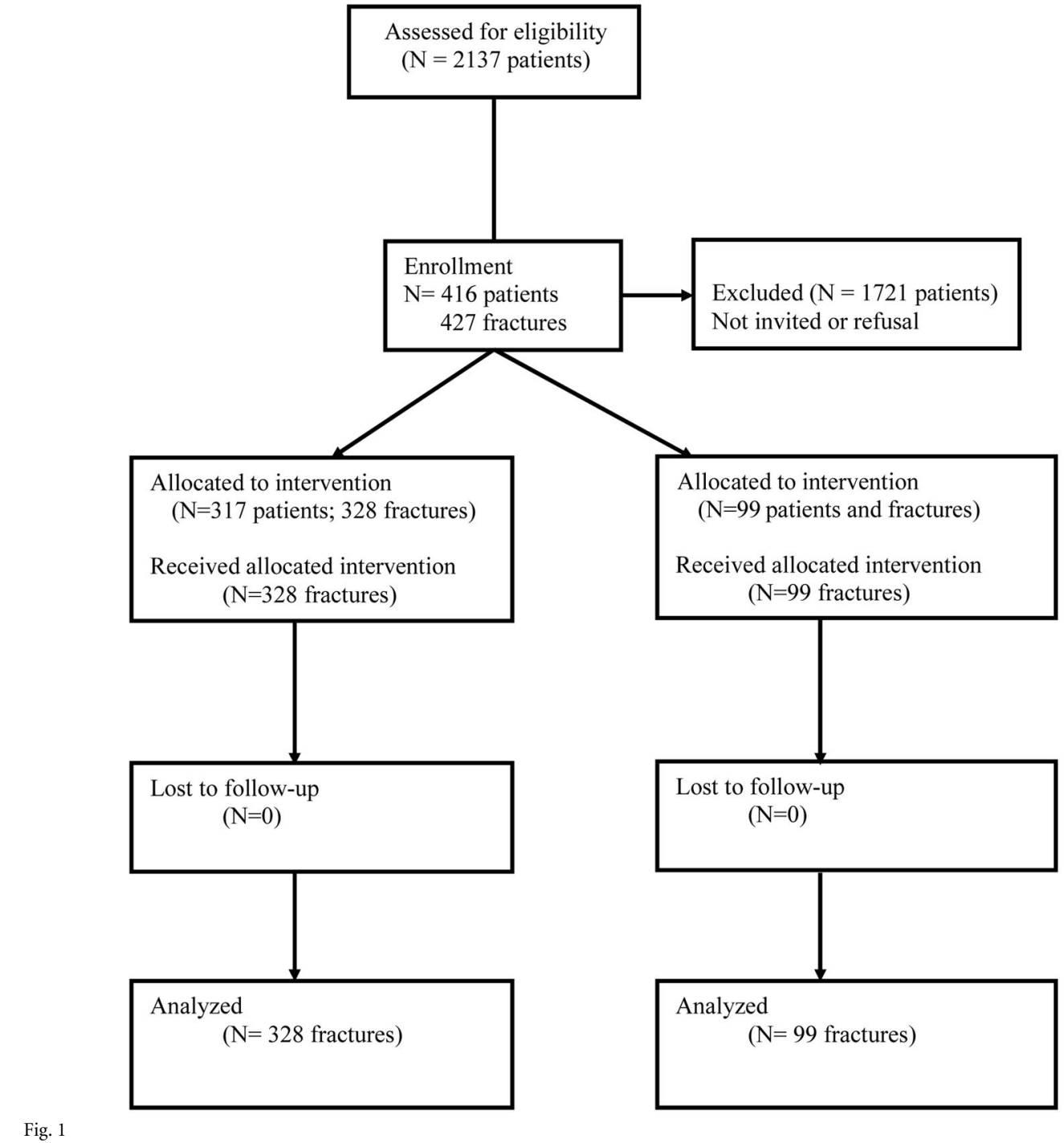

CONSORT E-Flowchart illustrating the trial profile. The CONSORT comprises a checklist and a flow diagram to help improve the quality of reports of randomized controlled trials, offering a standard way for researchers to report trials. 
The Journal of Bone \& JoInt Surgery - JBJS.org VOLUME 89-A · NUMBER 7 · JULY 2007
Can Vitamin C Prevent Complex Regional Pain

SyNdROME IN PATIENTS WITH WRist FraCtURES?

TABLE I Demographic Data

\begin{tabular}{|c|c|c|c|c|c|c|c|}
\hline & $\begin{array}{c}\text { Vitamin C } \\
200 \mathrm{mg} \\
(\mathrm{N}=96)\end{array}$ & $\begin{array}{c}\text { Vitamin C } \\
500 \mathrm{mg} \\
(\mathrm{N}=114)\end{array}$ & $\begin{array}{l}\text { Vitamin C } \\
1500 \mathrm{mg} \\
(\mathrm{N}=118)\end{array}$ & $\begin{array}{l}\text { Placebo } \\
(\mathrm{N}=99)\end{array}$ & $\begin{array}{c}\text { Vitamin C } \\
200 \mathrm{mg}, 500 \mathrm{mg}, \\
1500 \mathrm{mg} \\
(\mathrm{N}=328)\end{array}$ & P Value $\dagger$ & P Value \\
\hline Gender (no. of fractures) & & & & & & 0.796 & 0.431 \\
\hline Female & $80(83 \%)$ & $93(82 \%)$ & $100(85 \%)$ & 79 (80\%) & $273(83 \%)$ & & \\
\hline Male & $16(17 \%)$ & $21(18 \%)$ & $18(15 \%)$ & $20(20 \%)$ & 55 (17\%) & & \\
\hline Age* $(y r)$ & $62.8 \pm 17.2$ & $62.8 \pm 15.0$ & $62.4 \pm 18.3$ & $61.4 \pm 18$ & $62.7 \pm 16.8$ & 0.930 & 0.522 \\
\hline $\begin{array}{l}\text { Side of the fracture } \\
\text { (no. of fractures) }\end{array}$ & & & & & & 0.905 & 0.996 \\
\hline Right & 42 (44\%) & $55(48 \%)$ & $52(44 \%)$ & 45 (45\%) & 149 (45\%) & & \\
\hline Left & $54(56 \%)$ & $59(52 \%)$ & $66(56 \%)$ & 54 (55\%) & 179 (55\%) & & \\
\hline Dominance§ (no. of fractures) & & & & & & 0.946 & 0.687 \\
\hline Yes & $46(48 \%)$ & $51(45 \%)$ & $54(46 \%)$ & $48(48 \%)$ & $151(46 \%)$ & & \\
\hline No & $50(52 \%)$ & $63(55 \%)$ & $63(54 \%)$ & $51(52 \%)$ & $176(54 \%)$ & & \\
\hline Fracture type (no. of fractures) & & & & & & 0.571 & 0.447 \\
\hline $23-A$ & 57 (59\%) & 65 (57\%) & $57(48 \%)$ & $52(53 \%)$ & 179 (55\%) & & \\
\hline 23-B & $20(21 \%)$ & $23(20 \%)$ & $29(25 \%)$ & $18(18 \%)$ & $72(22 \%)$ & & \\
\hline $23-C$ & $19(20 \%)$ & $26(23 \%)$ & $32(27 \%)$ & $29(29 \%)$ & 77 (23\%) & & \\
\hline Dislocation (no. of fractures) & & & & & & 0.524 & 0.970 \\
\hline Yes & $58(60 \%)$ & 79 (69\%) & $81(69 \%)$ & $66(67 \%)$ & $218(66 \%)$ & & \\
\hline No & $38(40 \%)$ & $35(31 \%)$ & 37 (31\%) & $33(33 \%)$ & $110(34 \%)$ & & \\
\hline Reduction (no. of fractures) & & & & & & 0.150 & 0.861 \\
\hline Yes & $50(52 \%)$ & $76(67 \%)$ & $76(64 \%)$ & $60(61 \%)$ & 202 (62\%) & & \\
\hline No & $46(48 \%)$ & $38(33 \%)$ & $42(36 \%)$ & 39 (39\%) & $126(38 \%)$ & & \\
\hline Treatment (no. of fractures) & & & & & & 0.891 & 0.963 \\
\hline Conservative & $86(90 \%)$ & $99(87 \%)$ & $106(90 \%)$ & $88(89 \%)$ & $291(89 \%)$ & & \\
\hline Operative & $10(10 \%)$ & $15(13 \%)$ & $12(10 \%)$ & $11(11 \%)$ & 37 (11\%) & & \\
\hline $\begin{array}{l}\text { Complex regional pain } \\
\text { syndrome (no. of fractures) }\end{array}$ & & & & & & 0.007 & 0.002 \\
\hline Yes & $4(4 \%)$ & $2(2 \%)$ & $2(2 \%)$ & $10(10 \%)$ & $8(2.4 \%)$ & & \\
\hline No & $92(96 \%)$ & 112 (98\%) & $116(98 \%)$ & $89(90 \%)$ & 320 (97.6\%) & & \\
\hline
\end{tabular}

clinic again as there was no suspicion of a missed diagnosis of complex regional pain syndrome. None of the patients were lost to follow-up.

Twenty-five patients had been taking vitamin supplements prior to the fracture. Of these, nine had been taking vitamin B, two had been taking vitamin $D$, and thirteen had been taking a multivitamin preparation. None of those twenty-four patients had been consuming vitamin $\mathrm{C}$ in high doses (>50 mg daily, which is the recommended daily intake), and therefore none of them were excluded. The remaining patient had been taking $1000 \mathrm{mg}$ of vitamin C daily. She was asked to stop taking this supplement during the trial. In retrospect, she was randomized to $1500 \mathrm{mg}$ of vitamin C daily.

The prevalence of complex regional pain syndrome was $2.4 \%$ (eight of 328 ) in the vitamin C group and $10.1 \%$ (ten of ninety-nine) in the placebo group $(\mathrm{p}=0.002)$ (Table I). All of the affected patients were elderly women. For the entire cohort, the prevalence of complex regional pain syndrome was $4.2 \%$ (eighteen of 427).

Analysis of the different doses of vitamin $\mathrm{C}$ showed that the prevalence of complex regional pain syndrome in the 200mg group (4.2\%; four of ninety-six) was lower than that among those in the placebo group (10.1\%; ten of ninety-nine) (Table I), but this difference was not significant (relative risk, 0.41; $95 \%$ confidence interval, 0.13 to 1.27 ) (Table II). Significant differences were seen in the $500(\mathrm{p}=0.007)$ and $1500-\mathrm{mg}(\mathrm{p}=$ $0.005)$ groups, in which the relative risks of complex regional pain syndrome were 0.17 (95\% confidence interval, 0.04 to 0.77 ) and 0.17 (95\% confidence interval, 0.04 to 0.75 ), respectively. Overall, there was a significant difference between the vi- 
THE JOURNAL OF BONE \& JOINT SURGERY • JBJS.ORG Volume 89-A · NUmber $7 \cdot$ JULY 2007
Can Vitamin C Prevent Complex Regional Pain Syndrome in Patients With Wrist Fractures? tamin $\mathrm{C}$ group and the placebo group (relative risk, $0.24 ; 95 \%$ confidence interval, 0.10 to 0.60$)(\mathrm{p}=0.002)$ (Table II).

In the present study, all patients with complex regional pain syndrome were female; for male patients, the relative risk that complex regional pain syndrome would not develop was 0.95 (95\% confidence interval, 0.93 to 0.97 ). Complex regional pain syndrome occurred significantly more frequently in older patients (Table II).

One patient had a refracture and was randomized twice over an interval of four months, the first time to $500 \mathrm{mg}$ and the second time to $1500 \mathrm{mg}$ of vitamin C. Fracture treatment was nonoperative on both occasions, and complex regional pain syndrome did not develop.
One seventy-four-year-old patient in the 1500-mg vitamin $C$ group who had a fracture of both wrists had development of complex regional pain syndrome on the right side, where she had a simple AO 23-A2-type fracture that had been inadequately reduced. On the left side, where the patient had an adequately reduced $\mathrm{AO} 23-\mathrm{A} 3$-type fracture, there were no signs of complex regional pain syndrome.

Complex regional pain syndrome was not associated with the side of the fracture, dominance, the type of fracture, the need to undergo reduction, or the type of treatment (operative or nonoperative) (Table II).

Early complaints related to the plaster cast were predictive of the occurrence of complex regional pain syndrome (relative

\section{TABLE II Relative Risk of Complex Regional Pain Syndrome}

\begin{tabular}{|c|c|c|c|c|}
\hline Characteristic & $\begin{array}{l}\text { Complex Regional } \\
\text { Pain Syndrome } \\
(N=18)\end{array}$ & $\begin{array}{c}\text { No Complex } \\
\text { Regional Pain } \\
\text { Syndrome }(\mathrm{N}=409)\end{array}$ & $\begin{array}{l}\text { Relative Risk (95\% } \\
\text { Confidence Interval) }\end{array}$ & P Value \\
\hline Gender (no. of fractures) & & & $0.95(0.93 \text { to } 0.97)^{*}$ & \\
\hline Female & $18(100 \%)$ & $334(82 \%)$ & & \\
\hline Male & $0(0 \%)$ & 75 (18\%) & & \\
\hline Age $\dagger(y r)$ & $67.6 \pm 7.7$ & $62.1 \pm 17.4$ & & 0.011 \\
\hline Side of the fracture (no. of fractures) & & & 0.96 (0.39 to 2.39$)$ & \\
\hline Right & $8(44 \%)$ & $186(45 \%)$ & & \\
\hline Left & $10(56 \%)$ & $223(55 \%)$ & & \\
\hline Dominance $\ddagger$ (no. of fractures) & & & $1.14(0.46$ to 2.82$)$ & \\
\hline Yes & $9(50 \%)$ & $190(46 \%)$ & & \\
\hline No & 9 (50\%) & $218(53 \%)$ & & \\
\hline Fracture type (no. of fractures) & & & & 0.821 \\
\hline 23-A & $11(61 \%)$ & 220 (54\%) & & \\
\hline 23-B & $3(17 \%)$ & $87(21 \%)$ & & \\
\hline 23-C & $4(22 \%)$ & $102(25 \%)$ & & \\
\hline Dislocation (no. of fractures) & & & $1.31(0.48$ to 3.6$)$ & \\
\hline Yes & $13(72 \%)$ & $271(66 \%)$ & & \\
\hline No & $5(28 \%)$ & $138(34 \%)$ & & \\
\hline Reduction (no. of fractures) & & & $0.99(0.39$ to 2.5$)$ & \\
\hline Yes & $11(61 \%)$ & $251(61 \%)$ & & \\
\hline No & 7 (39\%) & $158(39 \%)$ & & \\
\hline Cast-related complaints (no. of fractures) & $11(61 \%)$ & $86(22 \%) \S$ & 5.35 (2.13 to 13.42$)$ & \\
\hline \multicolumn{5}{|l|}{ Prevention (no. of fractures) } \\
\hline Placebo & $10(56 \%)$ & $89(22 \%)$ & & \\
\hline Vitamin C 200 mg & $4(22 \%)$ & $92(22 \%)$ & $0.41(0.13$ to 1.27$)$ & \\
\hline Vitamin C 500 mg & $2(11 \%)$ & $112(27 \%)$ & $0.17(0.04$ to 0.77$)$ & \\
\hline Vitamin C $1500 \mathrm{mg}$ & $2(11 \%)$ & $116(28 \%)$ & $0.17(0.04$ to 0.75$)$ & \\
\hline Vitamin C overall & $8(44 \%)$ & $320(78 \%)$ & 0.24 (0.10 to 0.60$)$ & \\
\hline Treatment (no. of fractures) & & & $0.46(0.06$ to 3.41$)$ & \\
\hline Conservative & 17 (94\%) & $362(89 \%)$ & & \\
\hline Operative & $1(6 \%)$ & 47 (11\%) & & \\
\hline
\end{tabular}

*Relative risk calculated for no complex regional pain syndrome. †The values are given as the mean and the standard deviation. $¥$ This information was missing for one fracture. §Data on cast-related complaints were missing for fifteen fractures (with no complex regional pain syndrome), so this percentage is based on 394 fractures. 
The Journal of Bone \& JoInt Surgery - JBJS.org VOLUme 89-A · Number 7 • July 2007
Can Vitamin C Prevent Complex Regional Pain SyNdROME IN PATIENTS WITH WRist FraCtURES?

TABLE III Results of Logistic Regression Analysis

\begin{tabular}{|lcl|} 
& Odds Ratio (95\% Confidence Interval) & P Value \\
\hline Cast-related complaints & $5.73(2.11$ to 15.57$)$ & 0.001 \\
Vitamin C overall & $0.22(0.08$ to 0.58$)$ & 0.020 \\
Vitamin C $200 \mathrm{mg}$ & $0.38(0.11$ to 1.30$)$ & 0.122 \\
Vitamin C $500 \mathrm{mg}$ & $0.14(0.03$ to 0.68$)$ & 0.014 \\
Vitamin C $1500 \mathrm{mg}$ & $0.16(0.03$ to 0.77$)$ & 0.022 \\
\hline
\end{tabular}

risk, 5.35; 95\% confidence interval, 2.13 to 13.42 ). Overall, complex regional pain syndrome was diagnosed at an average of seventy-six days (range, thirty to 166 days) after the fracture (Fig. 2). The diagnosis of complex regional pain syndrome was made earlier for the patients in the vitamin $C$ group than for those in the placebo group (sixty-eight compared with eightythree days), but this difference was not significant.

The logistic regression analysis of the predictive factors yielded significant odds ratios for cast-related complaints and vitamin C doses of 500 and $1500 \mathrm{mg}$ daily (Table III).

\section{Discussion}

7 he present study confirms that vitamin $\mathrm{C}$ can have an in-

hibiting effect on the occurrence of complex regional pain syndrome after wrist fractures. Some limitations of the study should be mentioned.

The number of patients enrolled in the study was low in relation to the number of eligible patients who presented with wrist fractures, but after randomization no patient was lost to follow-up. It is difficult in an emergency department setting to motivate staff and patients to participate in any study. The possible lack of interest explains the high number of uninvited patients (961). Furthermore, during the informed-consent process, patients were informed about our previous study, which showed a positive effect of vitamin C. Therefore, 297 patients wanted to be sure that they received vitamin $C$ and decided not to participate in the study.

The confidence intervals for all reported values were wide. Our power analysis was based on our previous study ${ }^{3}$, but the prevalence of complex regional pain syndrome in the present study was lower than expected.

In The Netherlands, the intake of vitamin supplements is slowly increasing but is still low. Only twenty-five patients had already been taking vitamin supplements before the occurrence of the wrist fracture. None of them had been taking high-dose vitamin $\mathrm{C}$ (>50 mg daily) (except for the patient

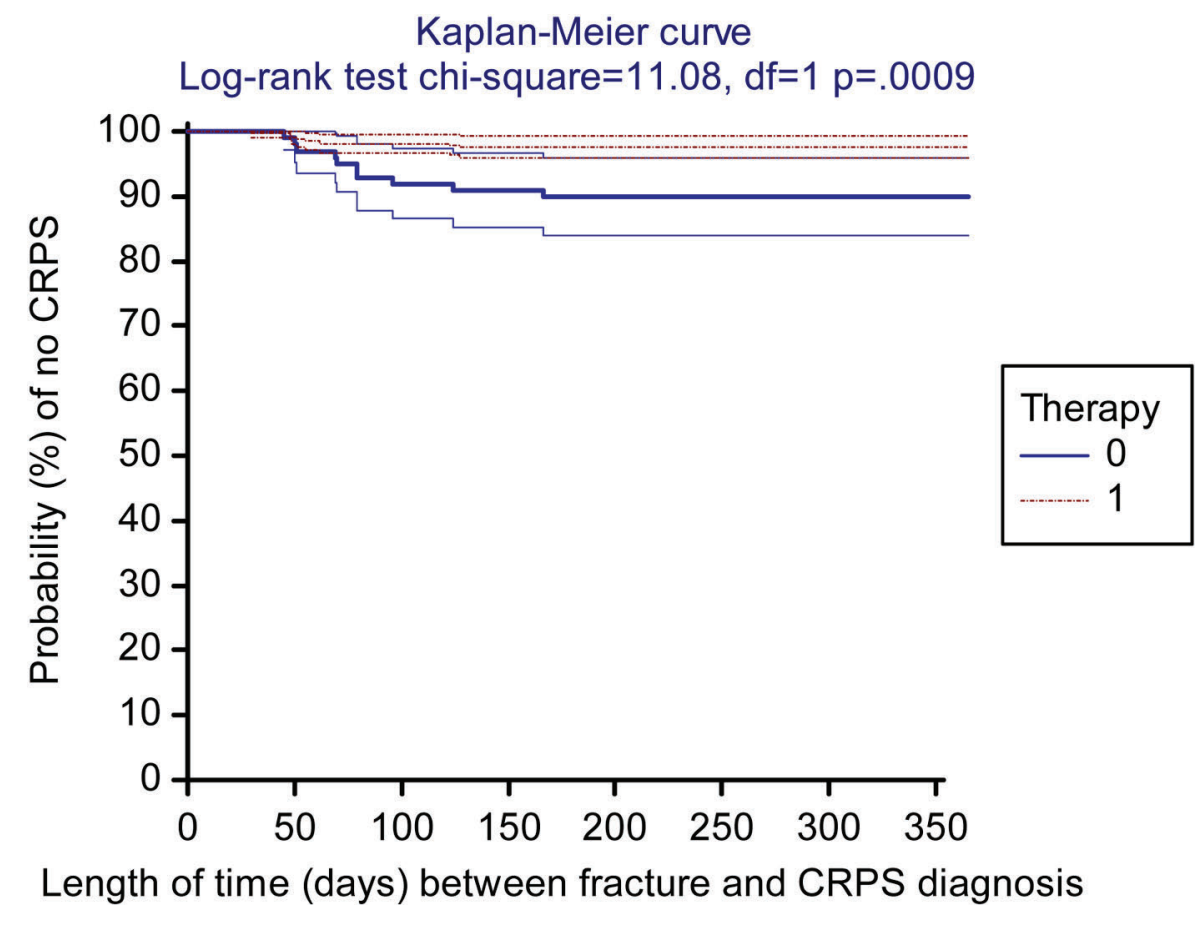

Fig. 2

Kaplan-Meier survivorship curves (with 95\% confidence intervals) for the vitamin $\mathrm{C}$ and placebo groups, with the occurrence of complex regional pain syndrome (CRPS) as the end point. $0=$ placebo, $1=$ vitamin $\mathrm{C}$, and $\mathrm{df}=$ degrees of freedom. 
ThE JOURNAL OF BONE \& JOINT SURGERY · JBJS.ORG Volume 89-A · NUmber $7 \cdot$ JULY 2007
Can Vitamin C Prevent Complex Regional Pain Syndrome in Patients With Wrist Fractures? mentioned earlier, who had been asked to stop doing so), and therefore none of those patients were excluded. Because of the low numbers of patients who were known to have been taking supplements before the fracture and the high doses that were used in the study, this source of bias was limited. It is known that vitamin $C$ rapidly reaches a steady state in human plasma at doses of $>200 \mathrm{mg}$ per day $\mathrm{y}^{5}$. With a normal dietary intake of 50 to $60 \mathrm{mg}$ of vitamin $\mathrm{C}$ per day added to our trial doses, we did not believe that there was a need to measure plasma levels of vitamin C. Compliance with taking the vitamins as recommended was not confirmed; however, all patients stated that they had consumed all fifty doses.

The overall prevalence of complex regional pain syndrome in the present study was $4.2 \%$, and the prevalence for the placebo group was $10.1 \%$. This rate in the placebo group is lower than those in our previous study ${ }^{3}(22 \%)$ and in the studies reported by Atkins et al. ${ }^{8,9}$ (25\% and 37\%, respectively). A possible explanation for the lower prevalence in the present study might be found in the more precise criteria (as described by Veldman et al. ${ }^{7}$ ) that we used for the diagnosis of complex regional pain syndrome. In the present study the diagnosis was made if four of five symptoms were present, whereas in our previous study the diagnosis was made if four of six symptoms were present. Clinicians in The Netherlands are more acquainted with the criteria of Veldman et al. ${ }^{7}$ than they are with other criteria such as those from the International Association for the Study of Pain (the so-called IASP criteria) or the modified research criteria proposed by Bruehl and others ${ }^{10,11}$. Another reason for the lower prevalence might be the fact that surgically treated wrist fractures were included in the present study. The number needed to treat (NNT) was 12 for the $500-\mathrm{mg}$ dose of vitamin $\mathrm{C}$ in this study.

We found that complaints related to the use of the plaster cast were strongly predictive of the development of complex regional pain syndrome. This finding has been described in previous studies ${ }^{3,12}$ and should alert physicians who treat fractures with a plaster cast. In the present study, all patients with complex regional pain syndrome were female, and this was significant in univariate analysis. From this observation that complex regional pain syndrome occurs more often in elderly women, the suggestion has been made that estrogen status could be a confounding factor ${ }^{3}$.

The mean time-interval between the wrist fracture and the diagnosis of complex regional pain syndrome was seventysix days for all cases. The mean interval was sixty-eight days for patients in the vitamin $\mathrm{C}$ group and eighty-three days for patients in the placebo group. The length of this time-interval is consistent with the results reported by Geertzen et al., who reported a mean interval of 2.3 months for the development of upper limb complex regional pain syndrome resulting from various causes ${ }^{13}$.

The pharmacodynamic behavior of vitamin $\mathrm{C}$ in the treatment of fracture or the prevention of complex regional pain syndrome is not fully understood. Nevertheless, previous studies have shown a positive effect of vitamin $\mathrm{C}$ in different healing processes. Yilmaz et al., in a study of experimental fractures in rats, suggested that vitamin $C$ enhanced fracture-healing in comparison with that in a control group $^{14}$, and Sarisozen et al. confirmed that vitamin C accelerated fracture-healing in rats ${ }^{15}$. We did not study the time needed for fracture-healing.

Ischemia-reperfusion injury is caused by endothelial and subendothelial damage by neutrophil-derived oxidants ${ }^{5}$. Kearns et al. noted that pretreatment with oral vitamin $\mathrm{C}$ protected against this injury in rats, possibly by diminishing neutrophil respiratory burst activity ${ }^{5}$. In a later study, they provided experimental evidence of a potential role for antioxidants, such as vitamin $\mathrm{C}$, in the reduction of injury to skeletal muscle caused by compartment syndrome ${ }^{16}$. With the knowledge that the production of oxidants in neutrophils is reduced by the administration of vitamin $\mathrm{C}$ and that vitamin $\mathrm{C}$ can protect the endothelium from direct injury by oxidants, one can postulate that it can prevent microvascular dysfunction and the microangiopathy of an inflammatory reaction as is seen in complex regional pain syndrome $e^{2,17-20}$.

The strength of our conclusion is limited by two issues. First, our two vitamin $\mathrm{C}$ studies yielded relative risks with wide confidence intervals, which must be interpreted as a lack of precision, limiting the validity of our conclusion. Second, with vitamin $\mathrm{C}$, we prevented a group of symptoms defined by us as complex regional pain syndrome. Due to the lack of precision with this diagnosis, we cannot be sure that we actually prevented complex regional pain syndrome.

In conclusion, we recommend the administration of 500 mg of vitamin C daily for fifty days after a wrist fracture because we believe that such treatment may prevent complex regional pain syndrome. Whether vitamin $\mathrm{C}$ can also be used as a treatment for complex regional pain syndrome should be the subject of further study.

NOTE: The authors thank all of the patients who participated in the study. Special thanks go to Jan Prins (pharmacist, Red Cross Hospital), Pieter Bakx, orthopaedic surgeon, and B.R.H. Jandebted to all of the surgeon, as a member of the Data and Safety Monitong Board. We are and we especially thank Michiel van de Rest, Guus Haeseker Agnita Stadhouder, Jacco van and we especially thank Michiel van de Rest, Guus Haeseker, Agnita Stadhouder, Jacco van
Doorn, and Niels Schep for clinical management. We thank Huub van der Meulen, surgeon, and Napoleon Coene, orthopaedic surgeon, at the Haga Hospital, and Maarten van der Elst, surgeon, and Rolf Bloem, orthopaedic surgeon, at the Reinier de Graaf Group. In addition, we surgeon, and Rolf Bloem, orthopaedic surgeon, at the Reinier de Graaf Group. In addition, we express our appreciation to Irene van der Sloot and Tineke Visser for collecting data. Lastly,
the authors thank the orthopaedic cast technicians Rob Schram, Ronald Deij, John Wissenburg, Peter van den Berg, and Han Goudappel. This work was kindly supported by a grant from Stichting Achmea Slachtoffer en Samenleving (SASS), a Dutch foundation for encouraging research objectives in relation to aid to victims. The separate medical ethics committees of the three hospitals approved the study.

\section{P.E. Zollinger, $\mathrm{MD}$}

Department of Orthopaedic Surgery, Ziekenhuis Rivierenland, President Kennedylaan 1, 4002 WP Tiel, The Netherlands. E-mail address: PE.Zollinger@tiscali.nl

W.E. Tuinebreijer, MD, PhD, MSc, MA

Relweg 59, 1949 EC Wijk aan Zee, The Netherlands

R.S. Breederveld, $\mathrm{MD}, \mathrm{PhD}$

R.W. Kreis, MD, PhD

Departments of Surgery (R.S.B., R.W.K.) and Burn Wounds (R.W.K.), Red Cross Hospital, Vondellaan 13, 1942 LE Beverwijk, The Netherlands 
The Journal of BOnE \& JOINT SURGERY · JBJS.ORG VOLUme 89-A · Number $7 \cdot$ July 2007
Can Vitamin C Prevent Complex Regional Pain

SyNdROME IN PATIENTS WITH WRist FraCtures?

\section{References}

1. Beal AL, Cerra FB. Multiple organ failure syndrome in the 1990s. Systemic inflammatory response and organ dysfunction. JAMA. 1994;271:226-33.

2. Tanaka $\mathrm{H}$, Matsuda T, Shimazaki $\mathrm{S}$, Matsuda $\mathrm{H}$. Vitamin $\mathrm{C}$ as a radical scavenger in the treatment of extensive burns. Int J Intensive Care. 1999;6:146-52.

3. Zollinger PE, Tuinebreijer WE, Kreis RW, Breederveld RS. Effect of vitamin C on frequency of reflex sympathetic dystrophy in wrist fractures: a randomised trial. Lancet. 1999;354:2025-8.

4. Tanaka H, Matsuda T, Miyagantani Y, Yukioka T, Matsuda H, Shimazaki S. Reduction of resuscitation fluid volumes in severely burned patients using ascorbic acid administration: a randomized, prospective study. Arch Surg. 2000;135:326-31.

5. Kearns SR, Moneley D, Murray P, Kelly C, Daly AF. Oral vitamin C attenuates acute ischaemia-reperfusion injury in skeletal muscle. J Bone Joint Surg Br. 2001;83:1202-6.

6. Müller ME, Nazarian S, Koch P, Schatzker J. The comprehensive classification of fractures of long bones. Berlin: Springer-Verlag; 1990.

7. Veldman PH, Reynen HM, Arntz IE, Goris RJ. Signs and symptoms of reflex sympathetic dystrophy: prospective study of 829 patients. Lancet. 1993;342: 1012-6.

8. Atkins RM, Duckworth T, Kanis JA. Algodystrophy following Colles' fracture. J Hand Surg [Br]. 1989;14:161-4.

9. Atkins RM, Duckworth T, Kanis JA. Features of algodystrophy after Colles' fracture. J Bone Joint Surg Br. 1990;72:105-10.

10. Merskey $\mathrm{H}$, Bogduk $\mathrm{N}$, editors. Classification of chronic pain: descriptions of chronic pain syndromes and definitions of pain terms. 2nd ed. Seattle: IASP Press; 1994

11. BruehI S, Harden RN, Galer BS, Saltz S, Bertram M, Backonja M, Gayles R, Rudin N, Bhugra MK, Stanton-Hicks M. External validation of IASP diagnostic criteria for Complex Regional Pain Syndrome and proposed research diag- nostic criteria. International Association for the Study of Pain. Pain. 1999 81:147-54

12. Field J, Protheroe DL, Atkins RM. Algodystrophy after Colles fractures is associated with secondary tightness of casts. J Bone Joint Surg Br. 1994;76: 901-5.

13. Geertzen JH, Dijkstra PU, Groothoff JW, ten Duis HJ, Eisma WH. Reflex sympathetic dystrophy of the upper extremity - a 5.5-year follow-up. Part I. Impair ments and perceived disability. Acta Orthop Scand Suppl. 1998;279:12-8.

14. Yilmaz $\mathrm{C}$, Erdemli E, Selek $\mathrm{H}$, Kinik $\mathrm{H}$, Arikan M, Erdemli B. The contribution of vitamin $\mathrm{C}$ to healing of experimental fractures. Arch Orthop Trauma Surg. 2001;121:426-8.

15. Sarisozen B, Durak K, Dincer G, Bilgen OF. The effects of vitamins $E$ and $C$ on fracture healing in rats. J Int Med Res. 2002;30:309-13.

16. Kearns SR, Daly AF, Sheehan K, Murray P, Kelly C, Bouchier-Hayes D. Oral vitamin $C$ reduces the injury to skeletal muscle caused by compartment syndrome. J Bone Joint Surg Br. 2004;86:906-11.

17. Herbaczynska-Cedro K, Wartanowicz M, Panczenko-Kresowska B, Cedro K, Klosiewicz-Wasek B, Wasek W. Inhibitory effect of vitamins C and E on the oxygen free radical production in human polymorphonuclear leucocytes. Eur J Clin Invest. 1994;24:316-9.

18. Matsuda T, Tanaka H, Hanumadass $M$, Gayle R, Yuasa H, Abcarian H, Matsuda $\mathrm{H}$, Reyes $\mathrm{H}$. Effects of high-dose vitamin $\mathrm{C}$ administration on postburn microvascular fluid and protein flux. J Burn Care Rehabil. 1992;13:560-6.

19. van der Laan L, Kapitein PJ, Oyen WJ, Verhofstad AA, Hendriks T, Goris RJ. A novel animal model to evaluate oxygen derived free radical damage in soft tissue. Free Radic Res. 1997;26:363-72.

20. Oyen WJ, Arntz IE, Claessens RM, Van der Meer JW, Corstens FH, Goris RJ. Reflex sympathetic dystrophy of the hand: an excessive inflammatory response? Pain. 1993;55:151-7. 